\title{
Evaluation of real time polymerase chain reaction assays for confirmation of Neisseria gonorrhoeae in clinical samples tested positive in the Roche Cobas Amplicor assay
}

\author{
S N Tabrizi, S Chen, M A Cohenford, B B Lentrichia, E Coffman, T Shultz, JW Tapsall, S M Garland
}

Sex Transm Infect 2004;80:68-71. doi: 10.1136/sti.2003.006239

See end of article for authors' affiliations

Correspondence to:

Sepehr Tabrizi, PhD, Department of Molecular Microbiology, The Royal Women's Hospital, 132 Grattan Street, Carlton, Victoria 3053, Australia; Sepehr.Tabrizi@ wch.org.au

Accepted for publication 22 August 2003

\begin{abstract}
Objective: Development of a rapid, sensitive, and accurate assay for confirmation of Neisseria gonorrhoeae in clinical samples.

Method: Two real time polymerase chain reaction (PCR) assays, developed on the LightCycler for amplification of the $\mathrm{N}$ gonorrhoeae cppB gene, were utilised for confirmation of this bacterial pathogen in samples positive by the Roche Cobas Amplicor assay. Performance characteristics of the two assays were compared with other commercial nucleic acid amplification assays, including the Abbott LCx and Roche 16S rRNA tests.

Results: All related Neisseria as well as other bacterial species tested negative by both cppB gene based assays, whereas $120 \mathrm{~N}$ gonorrhoeae clinical isolates from various geographical regions gave in positive results. Both assays had a sensitivity of one copy per reaction. 122 clinical samples positive and another 50 samples negative for $\mathrm{N}$ gonorrhoeae by Roche Cobas Amplicor were selected from a specimen pool of more than 3000 women tested previously. Overall, 73 of $122(59.8 \%)$ samples were confirmed as positive. The two real time assays had sensitivities of $99 \%$ and $100 \%$ and specificities of $98 \%$ and $100 \%$, respectively. The $16 \mathrm{~S}$ and LCx assays produced similar results to the real time assays, indicating a similar sensitivity to and specificity of both real time assays.

Conclusion: The data from this study highlight the need to confirm $N$ gonorrhoeae positive Cobas Amplicor PCR results as an important part of the testing algorithm of all diagnostic laboratories utilising this assay.
\end{abstract}

$\mathrm{N}$ eisseria gonorrhoeae causes one of the most prevalent bacterial sexually transmitted infections (STIs) in men and women. ${ }^{1}$ Laboratory testing is important for the aetiological diagnosis of gonococcal infection as clinical signs may overlap with other STIs. Also, a substantial proportion of gonococcal infections, especially in women, may be asymptomatic or present with minor non-specific symptoms. ${ }^{2}$ Therefore screening programmes are required in certain populations to ensure disease recognition and appropriate treatment. Laboratory diagnosis, based on culture, requires stringent specimen collection and transport conditions suitable for a fastidious organism. This can be difficult to achieve in some clinical situations, particularly with samples from remote areas where long transport times and harsh climatic conditions are present.

Sensitive and specific detection of $N$ gonorrhoeae is also possible using nucleic acid amplification tests (NAATs). NAATs do not depend on the presence of viable microorganisms and allow the use of several non-invasive sample collection methods. ${ }^{3-7}$ The Roche Cobas Amplicor is a commercial $N$ gonorrhoeae NAAT that targets the amplification of the cytosine DNA methyltransferase gene. Since this test has been shown to cross react with other Neisseria species, ${ }^{89}$ a confirmatory step is necessary for an accurate diagnosis. In this study we describe two real time confirmatory polymerase chain reaction (PCR) assays that are based on amplification of a nested region of $c p p$ B gene of the multicopy 4.2 kb cryptic plasmid. $^{3} 9^{10}$

\section{METHODS}

Bacterial strains and clinical samples

Assay specificity was performed on related and unrelated bacterial strains, including $N$ meningititis (groups $\mathrm{A}, \mathrm{B}, \mathrm{C}, \mathrm{W}$, and Y), $N$ subflava, $N$ flavescens, $N$ mucosa, $N$ lactamica, $N$ denitrificans, $N$ sicca, $N$ cinera, Campylobacter jejuni, Chlamydia trachomatis (serotypes $\mathrm{B}, \mathrm{C}, \mathrm{D}, \mathrm{E}, \mathrm{F}, \mathrm{G}, \mathrm{I}, \mathrm{K}$, and $\mathrm{L} 2$ ), C percori, C pneumoniae, C psittaci, Enterobacter cloacae, Escherichia. coli, Enterococcus faecalis, Proteus mirabilis, Staphylococcus epidermidis, and Trichomonas vaginalis. In addition, 120 ATCC and clinical strains of $N$ gonorrhoeae from Asia-Pacific, Australia, North America and Europe were used for confirmation of assay performance.

A 10-fold serial dilution of $N$ gonorrhoeae was also prepared and tested to assess sensitivity of the assays.

Clinical specimens used in this study comprised stored patient samples at the Royal Women's Hospital (RWH) in Melbourne, Australia. Approval was obtained from the RWH human research ethics committee for the STI testing of these samples, including the detection of $N$ gonorrhoeae. A total of 122 specimens testing positive for $N$ gonorrohoeae by Roche Cobas Amplicor (Roche Diagnostics, CA, USA) were selected from stored samples of more than 3000 women who had participated in various studies in Australia and Pacific islands. These positive specimens included 99 tampon, 14 urine, four urethral, and seven cervical samples. In addition, 50 samples negative by Cobas Amplicor assay were also randomly selected.

\section{Sample preparation}

DNA was extracted from each sample to avoid variations from endogenous inhibitors and to provide uniformity for testing in the various assay formats. Samples were extracted using the automated MagNA Pure LC (Roche Diagnostics) with the associated DNA Isolation Kit I protocol. DNA was eluted in a final volume of $100 \mu \mathrm{l}$ of MagNA Pure Elution Buffer (Roche Molecular Biochemical, Mannheim, Germany) 
Table 1 List of amplification tests and their target regions used for detection of $N$ gonorrhoeae

\begin{tabular}{llllll}
\hline Test & Manufacturer & Gene target & Location & Assay & Amplicon size \\
\hline Cobas & Roche & $\begin{array}{l}\text { Cytosine DNA } \\
\text { methyltransferase gene }\end{array}$ & Genomic & PCR & 201 \\
Amplicor & & 16S rRNA & Genomic & PCR & 413 \\
$16 S$ & Roche & opa gene & Genomic & LCR & 48 \\
LCx & Abbott & cppB gene & Cryptic plasmid & Real time PCR & 273 \\
LightCycler- & In-house & cppB gene & Cryptic plasmid & Real time PCR & 90 \\
FRET & & & & &
\end{tabular}

and was tested via various assays targeting different regions as outlined in table 1 .

\section{Roche Cobas Amplicor, 16S rRNA assay, and Abbott LCx assays}

Both Roche Cobas Amplicor and 16S assays were performed on extracted DNA as described previously. ${ }^{11}$ For Abbott LCX assay, an aliquot of $10 \mu \mathrm{l}$ of DNA was added to $90 \mu \mathrm{l}$ of Urine Resuspension Buffer (Abbott Diagnostics, Abbott Park, IL, USA) and incubated at $97^{\circ} \mathrm{C}$ for 15 minutes before amplification and detection. Subsequent amplification and detection were done as per Abbott LCx procedures (Abbott Diagnostics) described by the manufacturer.

\section{Real time assays}

Detection of the $\beta$ globin gene sequence was performed as a positive internal control. This PCR reaction is directed to amplify a human $\beta$ globin gene product of $260 \mathrm{bp}$ using a rapid real time PCR (LightCycler, Roche Molecular Biochemicals). Amplification was performed in capillaries in a total volume of $10 \mu \mathrm{l}$ consisting of $2 \mu \mathrm{l}$ of extracted DNA, $0.5 \mu \mathrm{M}$ of each primer GH20-PC04, ${ }^{12} \mathrm{~lx}$ LightCycler-Fast Start Master Sybr Green 1 (Roche Molecular Biochemicals) and $2.5 \mathrm{mM} \mathrm{MgCl}$. The samples were heated at $95^{\circ} \mathrm{C}$ for 10 minutes and cycled 45 times using parameters of $95^{\circ} \mathrm{C}$ for 0 seconds, $55^{\circ} \mathrm{C}$ for 10 seconds, and $72^{\circ} \mathrm{C}$ for 10 seconds. Fluorescence was acquired once each cycle at the end of the extension segment. A DNA melting curve was appended to the end of the amplification reaction to characterise the amplified product. Adequate amplifiable DNA in the sample was indicated by the presence of peak at a melting temperature of $88^{\circ} \mathrm{C}$ for the $\beta$ globin gene sequences.

Amplification reaction of $N$ gonorrhoeae DNA sequences using fluorescence resonance energy transfer (FRET) probes consisted of $2 \mu \mathrm{l}$ aliquot of extracted DNA, 1x LightCycler Fast Start Reaction Mix (Roche) containing $2.5 \mathrm{mM} \mathrm{MgCl} 2$ (final concentration), and $0.5 \mu \mathrm{M}$ of each primer NGl and $\mathrm{NG}^{3}$ directed at amplifying a $273 \mathrm{bp}$ fragment of the $\operatorname{cppB}$ gene in a total of $10 \mu \mathrm{l}$ (table 1). This $273 \mathrm{bp} \operatorname{cppB}$ gene fragment is carried within the bacterial chromosome, as well as the $4.2 \mathrm{~kb}$ cryptic plasmid. The reactions also included $0.2 \mu \mathrm{M}$ of hybridisation probes NG-F1S 5' TGAACAGCCCTGCTATGACTATCAACC 3' (3'fluorescein labelled) and acceptor 5' fluorophore LC640 labelled NGF2S 5' TGCCGCCGATATACCTAGCAAGC 3'. The samples were heated at $95^{\circ} \mathrm{C}$ for 10 minutes and cycled 45 times using parameters of $95^{\circ} \mathrm{C}$ for 0 seconds, $60^{\circ} \mathrm{C}$ for 10 seconds, and $72^{\circ} \mathrm{C}$ for 10 seconds. The presence of an amplification curve and a melting curve peak at $67^{\circ} \mathrm{C}$ confirmed presence of the $N$ gonorrhoeae $c p p B$ gene sequences in the sample.

Amplification reactions for $N$ gonorrhoeae DNA sequences using molecular beacon (MB) technology contained a $2 \mu \mathrm{l}$ aliquot of extracted DNA, 1x LightCycler Fast Start Reaction Mix (Roche) containing $2.5 \mathrm{mM} \mathrm{MgCl}_{2}$ (final concentration), and $1 \mu \mathrm{M}$ each of GC20 5'-GTCTTCGTTTCCAACAGGTCTA-3' and GC22 5'-TAGCGATATGGAGCGTCAAG- 3 ' in a total reaction volume of $10 \mu \mathrm{l}$. The primers amplify a $90 \mathrm{bp}$ DNA sequence nested within a previously described $390 \mathrm{bp}$ region of cppB gene ${ }^{10}$ and the $273 \mathrm{bp}$ amplification products of the FRET probe assay (table 1). The reactions also included $50 \mathrm{nM}$ (final concentration) of the FAM and DABCYL labelled 42-mer molecular beacon probe: 5' TGGACGCTCTGTTTCGGCTCTCTGCTGTTTCAAGTCCA 3'. The samples were heated at $95^{\circ} \mathrm{C}$ for 10 minutes and cycled 45 times using parameters of $95^{\circ} \mathrm{C}$ for 0 seconds, $55^{\circ} \mathrm{C}$ for 10 seconds, and $72^{\circ} \mathrm{C}$ for 10 seconds. Fluorescence was acquired once each cycle at the end of the annealing segment. All samples, which yielded linear increases in their fluorescence readings relative to the negative control sample (no $N$ gonorrhoeae DNA), were considered positive.

Consensus positivity among the clinical samples tested by the above methods was defined as any sample being positive by at least two out of the four other methods used besides Cobas Amplicor PCR.

Strict procedures avoiding specimen contamination and carryover were followed.

\section{RESULTS}

The real time PCR using LightCycler with FRET and MB probes were compared to three other methods for detection of $N$ gonorrhoeae. All 120 clinical $N$ gonorrhoeae strains utilised in $\mathrm{MB}$ and FRET probe assays were positive. None of the other Neisseria species or other bacterial species tested were positive by either of these assays.

Both MB and FRET assays produced real time amplification curves allowing rapid identification of positive samples (fig 1). The analytical sensitivity of both real time assays, measured by a serial 10 -fold dilution of the $N$ gonorrhoeae bacterial DNA, demonstrated the sensitivity of one copy per reaction for both assays (fig 1 ).

Each of the 172 samples, previously tested by the Roche Cobas Amplicor assay, were positive for the human $\beta$ globin, indicating the presence of adequate amplifiable DNA in the specimen. Only 73 out of 122 (59.8\%) Cobas Amplicor positive samples were confirmed to be positive by the two out of four consensus criteria (table 2). In addition, 50 Cobas Amplicor PCR negative samples were tested by the MB and FRET assays with one sample showing positivity with all methods tested except Cobas and 16S rRNA assays. Because of high false positivity rate of Cobas Amplicor results, the initial results were stratified according to optical density levels. The confirmation rate was found to be proportional to the optical density of the Cobas PCR with highest confirmation of $93.5 \%$ being obtained with samples having optical density (OD) of higher than 3.5 (table 2). Four consensus positive samples were negative by $\mathrm{LCx}$ reflecting a possible inhibition of amplification by ligase chain reaction.

Using the consensus results as the gold standard, the FRET and MB probe assays had a sensitivity of $99 \%$ and $100 \%$ respectively and specificity of $98 \%$ and $100 \%$ respectively. The 

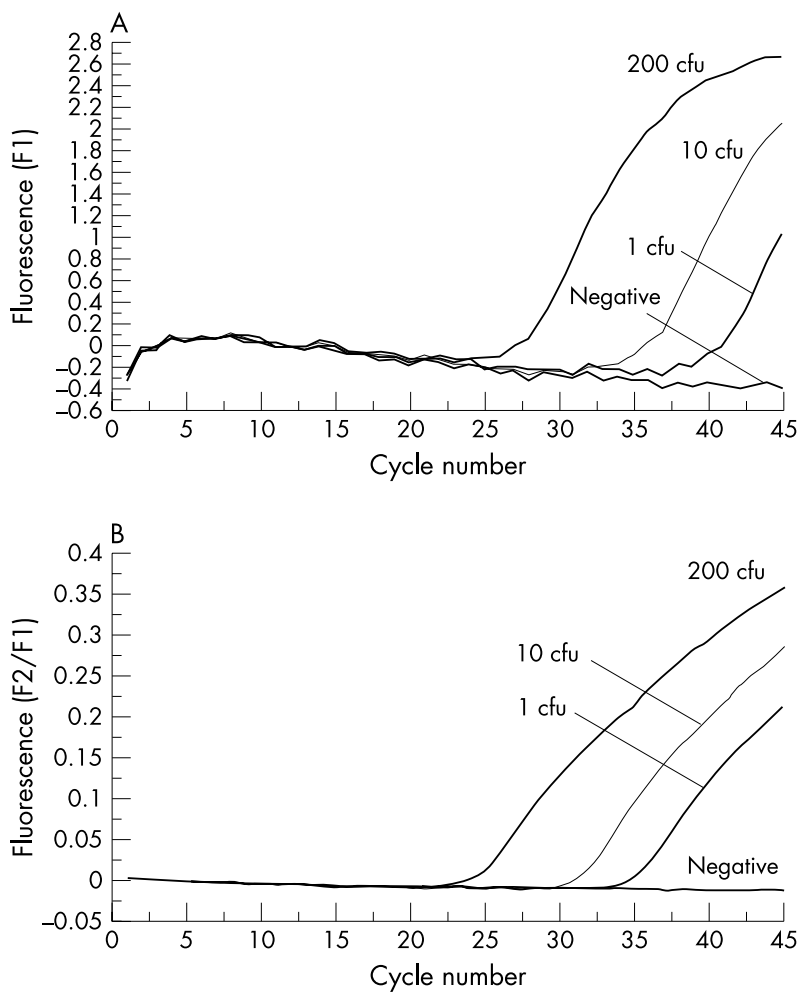

Figure 1 Amplification curves generated from dilutions of $N$ gonorrhoeae on LightCycler using (A) MB probe by detection of florescence at $530 \mathrm{nM}$ and (B) FRET probe by detection of fluorescence at $640 \mathrm{nM}$ (background adjusted ratio at $640 / 530 \mathrm{nM}$ is shown).

16s rRNA and LCx assays produced similar results to the real time assays indicating a comparable sensitivity, specificity, positive and negative predictive values to the FRET and the MB probe methods (table 3).

\section{DISCUSSION}

Accurate and sensitive assays for the diagnosis of $N$ gonorrhoeae infection are important for the clinical management of patients. Currently there are a number of commercial
NAATs available. However, validation of these assays for specific specimen types and sites is often lacking and this restricts their application. Some assays, such as the Roche Cobas Amplicor test, require a confirmatory test to obtain an accurate and reliable diagnosis. The popularity of the Roche Cobas assay can be attributed primarily to its ability to test for both chlamydial and gonococcal infections in a single multiplexed PCR with an internal control for inhibition every sample. The Cobas Amplicor assay has, however, been shown to cross react with isolates of certain non-pathogenic Neisseria species ( $N$ subflava and $N$ cinerea) and lactobacilli (especially in specimens with heavy bacterial loads). ${ }^{8}$ Despite the suggested strategy to reduce the number of false positive results by expanding the read-out region defining a grey zone result, false positive and negative results can still occur with substantial frequency. ${ }^{13}$ Confirmation of Cobas PCR results by a supplementary 16S rRNA assay was one approach introduced by Roche but this test was recently discontinued by the manufacturer. In addition, LCX, which could have been utilised as a confirmatory assay, was also discontinued because of manufacturing issues. Consequently laboratories performing $N$ gonorrhoeae NAAT needed to select or develop a supplementary assay for confirmation of positive results or else report all positives without confirmation.

Several studies have described assays targeting amplification of the $4.2 \mathrm{~kb}$ cryptic plasmid which is reported to be present in $96 \%$ of clinical isolates of $N$ gonorrhoeae. ${ }^{14}$ This cryptic plasmid is, in theory, an acceptable target for confirmatory testing since it has been shown to be present as both an integrated form at multiple sites as well as an episomal form making the assay more sensitive. ${ }^{15}$

In this study we present data for two accurate, sensitive, and rapid real time assays based on amplification of $c p p \mathrm{~B}$ gene of $N$ gonorrhoeae. All 120 clinical strains of $N$ gonorrhoeae from various geographical regions were detected, indicating that this plasmid target may be suitable for detection of the majority of isolates in the region. Further, the two NAATs did not amplify DNA from other bacterial species or other Neisseria species indicating that both these assays are very specific for $N$ gonorrhoeae. Testing clinical samples and comparisons with other commercial assays demonstrated accurate detection by both the FRET and the MB assays. Almost $40 \%$ of the Roche Cobas Amplicor positive samples

Table 2 Comparative results of various amplification assays on clinical samples for detection of $\mathrm{N}$ gonorrhoeae stratified by optical density (OD) of Cobas assay

\begin{tabular}{lllllllll}
\hline \multicolumn{7}{c}{ Number of positive specimen } \\
\cline { 3 - 8 } Cobas OD & $\begin{array}{l}\text { Specimen } \\
\text { number tested }\end{array}$ & Cobas & 165 & LCx & LC-FRET & LC-MB & $\begin{array}{l}\text { Consensus } \\
\text { (2 out or 4) }\end{array}$ & \% Confirmed \\
\hline$<0.2$ & 50 & 0 & 0 & 1 & 1 & 1 & 1 & N/A \\
$0.2-2.0$ & 33 & 33 & 2 & 0 & 0 & 0 & 0 & 0 \\
$>2.0-3.5$ & 27 & 27 & 14 & 14 & 14 & 14 & 14 & 51.8 \\
$>3.5$ & 62 & 62 & 57 & 54 & 57 & 58 & 58 & 93.5 \\
Total & 172 & 122 & 73 & 69 & 72 & 73 & 73 & 59.8 \\
\hline
\end{tabular}

Table 3 The MB and FRET assay performance relative to the LCX and 16sRNA methods

\begin{tabular}{|c|c|c|c|c|}
\hline & Sensitivity (\%) & Specificity (\%) & $\begin{array}{l}\text { Positive predictive } \\
\text { value (\%) }\end{array}$ & $\begin{array}{l}\text { Negative predictive } \\
\text { value }(\%)\end{array}$ \\
\hline MB vl6s rRNA & 97.26 & 97.98 & 97.26 & 97.98 \\
\hline FRET $v 16 s$ rRNA & 95.89 & 97.98 & 97.22 & 97.00 \\
\hline$M B v * L C x$ & 100 & 96.08 & 94.37 & 100 \\
\hline FRET $v$ *LCx & 100 & 96.08 & 94.37 & 100 \\
\hline
\end{tabular}

*Denotes that three specimens were omitted from the analysis because of insufficient material. 


\section{Key messages}

- Accurate and sensitive assays for the diagnosis of $N$ gonorrhoeae infection are important for the clinical management of patients

- NAAT assays are being used more for diagnosis and some assays require a confirmatory assay for diagnosis of $N$ gonorrhoeae

- Real time PCR assays, as described, are adequate supplementary assay alternatives for detection and confirmation of $\mathrm{N}$ gonorrhoeae, which allow appropriate treatment of infected patients

could not be confirmed as positive by the FRET and MB assays. These samples were shown to be false positives, since they also tested negative by the 16S rRNA PCR and LCx assays. This high false positive rate demonstrates an ongoing problem with the Cobas Assay for detection of $N$ gonorrhoeae and highlights the importance of confirmation of all positive results by a supplementary assay. A proposed modification of the Roche Cobas Amplicor $N$ gonorrhoeae assay intended to improve its accuracy involved setting the positive optical density threshold from $>0.8$ to 3.5 or more. Although an improvement was achieved, a $6 \%$ false positive rate was still observed and over $50 \%$ of samples with an equivocal OD (between 0.2 and 0.8 ) required retesting. ${ }^{13}$ Application of this threshold in our study would have resulted in a false positive rate of $6.5 \%$.

In this study, four samples were negative by LCx but produced a positive result by two or more of the other tests. An inhibitor in these samples affecting the LCR reaction could be responsible for this result.

It is important to be aware that some strains of $N$ gonorrhoeae lack the cryptic plasmid. ${ }^{14}{ }^{15}$ However, in this study none of the strains nor the confirmed clinical samples with $N$ gonorrhoeae gave a false negative result using the consensus definition. Inevitably some true positives in the Roche Cobas Amplicor assay will not be confirmed by the $c p p B$ assays. Since the distribution of gonococcal subtypes, including those known to contain the $\operatorname{cpp} B$ gene, is nonrandom, experiential data will be required to determine whether the frequency of failure to confirm positive Cobas Amplicor results was the result of gonococci lacking this amplification target. Affirmation of cryptic plasmid deficient gonococci may be achieved by further examination of culture positive but $c p p B$ gene negative by nucleic acid amplification. It has also been observed that homology also exists between the sequences of the $N$ gonorrhoeae cryptic plasmid and the plasmids present in other species of Neisseria ${ }^{16}{ }^{17}$; however, we did not observe false positives in the sample population studied. The cost effectiveness and ease of use of the multiplexed Cobas PCR method with its internal control are important reasons for the commercial success of the Roche assay. Implementation of a real time assay, as highlighted in this study, should be an important part of the testing algorithm for all clinical diagnostic laboratories utilising this assay. Alternative commercial assays, such as those available through Gen Probe and Beckton Dickinson, can also be utilised for such confirmation, although the cost of performing these assays needs to be considered.

\section{ACKNOWLEDGEMENTS}

We thank Abbott Diagnostics for providing diagnostic kits to perform these assays; Dr Guillermo E Madico from Boston University for his help in providing us with different Neisseria species. SNT receive support from molecular microbiology research funds.

\section{CONTRIBUTORS}

SNT, overall design of study including FRET probe based assay; SC conducted real time PCR assays; MAC, design of MB real time assay, $\mathrm{BBL}$, design of $\mathrm{MB}$ real time assay; $\mathrm{EC}$, design of $\mathrm{MB}$ real time assay; TS contributed to study design and supplied gonorrhoea strains; JWT contributed to study design and supplied gonorrhoea strains; SMG, study design and overall supervision of the project

\section{Authors' affiliations}

S N Tabrizi, S Chen, S M Garland, Department of Molecular Microbiology, The Royal Women's Hospital, Victoria 3053, Australia M A Cohenford, B B Lentrichia, E Coffman, CYTYC Corporation, 85 Swanson Road, Boxborough, MA 01719, USA

T Sulz, J W Tapsall, Department of Microbiology, South Eastern Area Laboratory Services, The Prince of Wales Hospital, Randwick, New South Wales 2031, Australia

\section{REFERENCES}

1 Gerbase AC, Rowley JT, Heymann DH, et al. Global prevalence and incidence estimates of selected curable STDs. Sex Transm Infect 1998;74:S12-S16.

2 Korenromp EL, Sudaryo MK, de Vlas SJ, et al. What proportion of episodes of gonorrhoea and chlamydia becomes symptomatic? Int J STD AIDS 2002;13:91-101.

3 Tabrizi SN, Paterson B, Fairley CK, et al. Garland. Self-administered technique for the detection of sexually transmitted diseases in remote communities. J Infect Dis 1997; 176:289-92.

4 Rompalo AM, Gaydos CA, Shah N, et al. Evaluation of use of a single intravaginal swab to detect multiple sexually transmitted infections in activeduty military women. Clin Infect Dis 2001;33:1455-61.

5 Tabrizi SN, Paterson B, Fairley CK, et al. Comparison of tampon and urine as self-administered methods of specimen collection in detection of Chlamydia trachomatis, Neisseria gonorrhoeae and Trichomonas vaginalis in women. Int J STD AIDS 1998:9:347-9.

6 Schachter J. Urine as a specimen for diagnosis of sexually transmitted diseases. Am J Med 1983;75:93-7.

7 Knox J, Tabrizi SN, Miller P, et al. Evaluation of self-collected samples in contrast to practitioner-collected samples for detection of Chlamydia trachomatis, Neisseria gonorrhoeae, and Trichomonas vaginalis by polymerase chain reaction among women living in remote areas. Sex Transm Dis 2002;29:647-54

8 van Doornum GJ, Schouls LM, Pijl A, et al. Comparison between the LCx Probe system and the Cobas Amplicor system for detection of Chlamydia trachomatis and Neisseria gonorrhoeae infections in patients attending a clinic for treatment of sexually transmitted diseases in Amsterdam, the Netherlands. J Clin Microbiol 2001;39:829-35.

9 Farrell DJ. Evaluation of Amplicor Neisseria gonorrhoeae PCR using cppB nested PCR and 16S rRNA PCR. J Clin Microbiol 1999;37:386-90.

10 Ho BSW, Feng WG, Wong BKC, et al. Polymerase chain reaction for the detection of Neisseria gonorrhoeae in clinical samples. J Clin Pathol 1992;45:439-42.

11 Tabrizi SN, Fairley CK, Cehn S, et al. Evaluation of patient-administered tampon specimens for Chlamydia trachomatis and Neisseria gonorrhoeae. Sex Transm Dis 2000;27:133-7.

12 Resnick RM, Cornelissen MT, Wright DK, et al. Detection and typing of human papillomavirus in archival cervical cancer specimens by DNA amplification with consensus primers. J Natl Cancer Inst 1990;82:1477-84.

13 Van Der Pol B, Martin DH, Schachter J, et al. Enhancing the specificity of the Cobas Amplicor CT/NG test for Neisseria gonorrhoeae by retesting
specimens with equivocal results. J Clin Microbiol 2001;39:3092-8.

14 Roberts M, Piot P, Falkow S. The ecology of gonococcal plasmids. Gen Microbiol 1979;114:491-4.

15 Hagblom $P$, Korch $C$, Jonsson $A B$, et al. Intragenic variation by site-specific recombination in the cryptic plasmid of Neisseria gonorrhoeae. J Bacteriol 1986;167:231-7.

16 Ison CA, Bellinger CM, Walker J. Homology of cryptic plasmid of Neisseria gonorrhoeae with plasmids from Neisseria meningitidis and Neisseria lactamica. J Clin Pathol 1986;39:1 119-23.

17 Palmer HM, Mallinson H, Wood RL, et al. Evaluation of the specificities of five DNA amplification methods for the detection of Neisseria gonorrhoeae. J Clin Microbiol 2003;41:835-7. 